\title{
Introduction to the Special Series on Booster Sessions and Long-Term Maintenance of Treatment Gains
}

\author{
David J. Kolko • Oliver Lindhiem
}

Published online: 12 January 2014

(C) Springer Science+Business Media New York 2014

In 1998, Eyberg and colleagues conducted a review of the literature of booster sessions and other maintenance strategies for enhancing the long-term maintenance of treatment effects for parent training programs. This timely review concluded with a call for more studies examining: 1) the long-term maintenance of treatment effects, and 2) the need to test the incremental benefit of booster sessions using randomized control group designs. Ten years later, an updated review by Eyberg and colleagues (2008) of treatments for disruptive behavior reported that most of the interventions included in that review had shown maintenance of treatment gains for at least a year after treatment had ended, but that many of the follow-up studies included designs that were only modestly rigorous. They suggested the need to explore alternative designs that would permit careful evaluation of disruptive behavior over time to document more rigorously maintenance effects. This special series is a step towards providing a response to this call.

All four papers in this special series address the first of these two recommendations (i.e. long-term maintenance of treatment effects) and three specifically test the utility of booster sessions using a randomized control group design. Dishion and colleagues (2013) report on the long-term maintenance of benefits from yearly Family Check-Ups (FCUs) in a multiethnic sample of high-risk families. Eyberg and colleagues (2014) examine a continuing care model of maintenance treatment following Parent-child Interaction Therapy (PCIT) for families of young children. Young children

\footnotetext{
D. J. Kolko $(\bowtie) \cdot$ O. Lindhiem

Department of Psychiatry, University of Pittsburgh School of

Medicine, 3811 O'Hara Street, Pittsburgh, PA 15213, USA

e-mail: kolkodj@upmc.edu

O. Lindhiem

e-mail: lindhiemoj@upmc.edu
}

diagnosed with oppositional defiant disorder (ODD) who completed the original treatment were then randomized to PCIT maintenance treatment (MT) or to an assessment-only follow-up condition (AO). Maintenance treatment consisted of monthly telephone contact to monitor progress and provide additional booster support. Lochman and colleagues (2013) report on a child-oriented booster intervention with children who had previously received an abbreviated version of the Coping Power program in the $5^{\text {th }}$ grade. The booster sessions consisted of non-manualized, brief monthly individual contact. Finally, Kolko and colleagues (2013) examine the impact of a brief booster treatment that was delivered 3 years after an acute treatment for clinically referred boys and girls originally diagnosed with Oppositional Defiant Disorder (ODD) or Conduct Disorder (CD). At the conclusion of the acute treatment and 3-year follow-up period (i.e., study month 42), the sample was re-randomized into Booster treatment or Enhanced Usual Care and then assessed through two years follow-up. Although these studies vary widely on specific parameters, all share a randomized design and empirical effort to examine the long-term maintenance of treatment/prevention effects and/or the incremental benefit of booster sessions for children with disruptive behavior problems and their families.

There are many parameters that are relevant to the evaluation of booster or sessions or maintenance treatment, many of which are represented in the studies described in this special issue. These include the timing of sessions (when to begin booster sessions), frequency of sessions, dose (both number and length of sessions), and modality (e.g. office visits versus phone check-ups). Another important consideration is whether booster sessions should be administered to all participants or a just a subgroup of participants (perhaps those who have failed to maintain their initial treatment gains). Other considerations include whether or not to introduce new treatment content and/or select new or revised treatment goals. For 


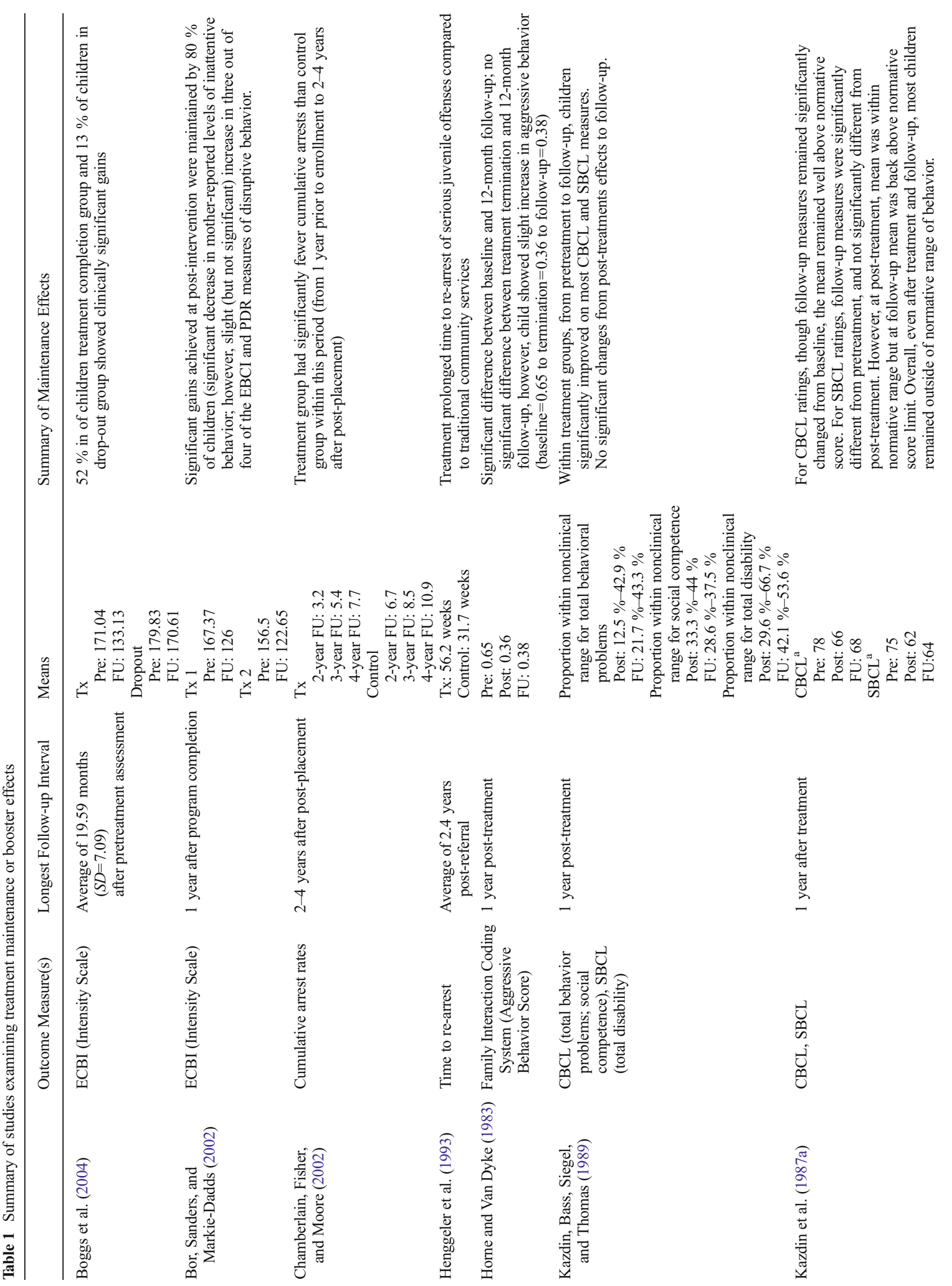




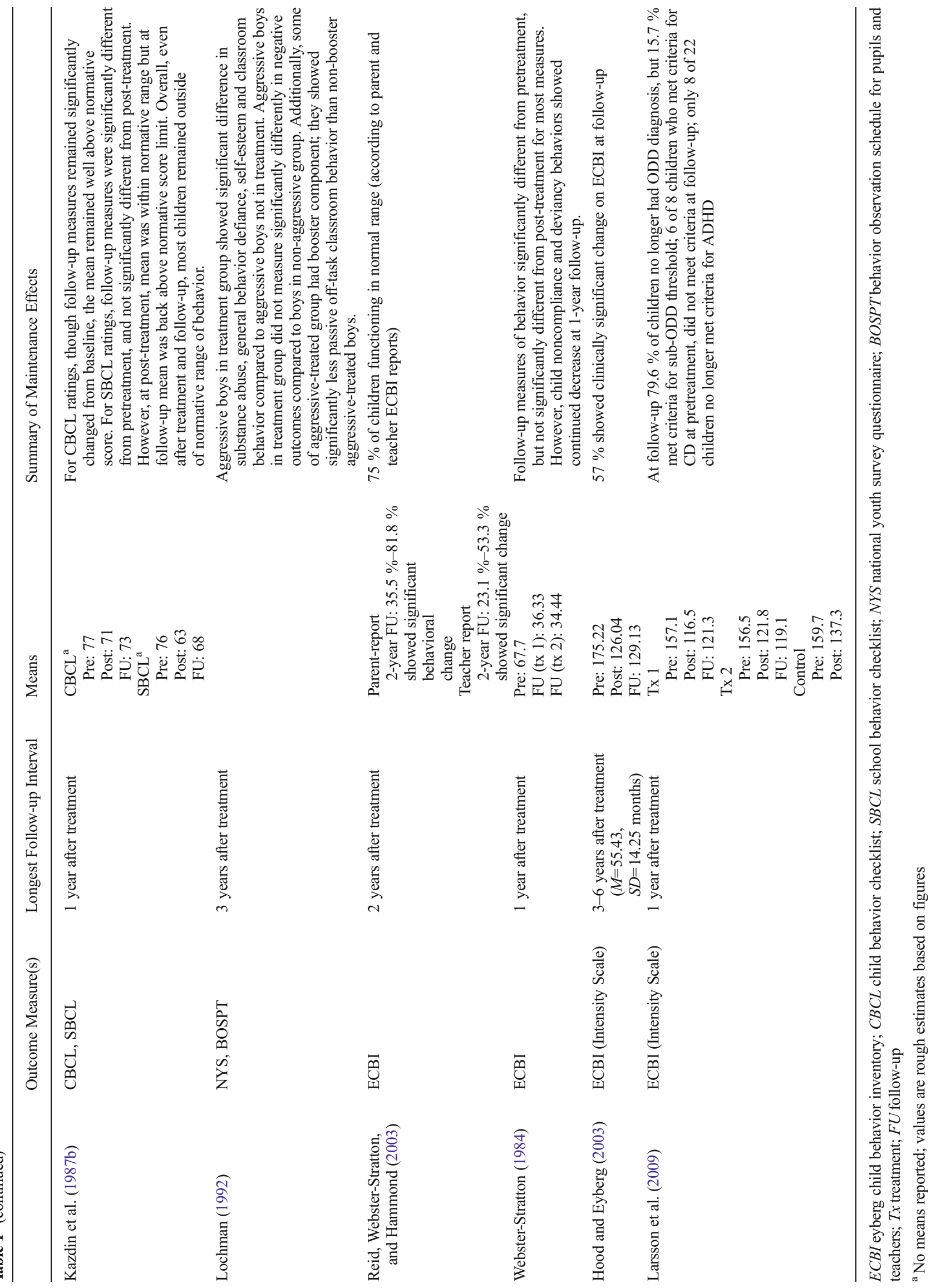


purposes of providing some background on these and other parameters, we have included a description of the key parameters of several early and more recent studies reporting on the effects of treatment maintenance or booster treatment effects in Table 1. These few studies may provide a context for understanding some of the strengths and limitations of the research conducted in this area, as well as for appreciating the four studies included in this series.

Finally, the series includes a commentary by Patrick Tolan (2014), who has conducted one the few studies designed to evaluate the incremental benefits of a booster intervention for school students that was conducted in the context of a prevention trial with high risk youth (Tolan et al., 2009). He provides an informed perspective on the role of booster or maintenance that incorporates his review of the four papers included in this series and his understanding of the longterm course of disruptive behavior disorders and juvenile delinquency.

We hope that this series provides the reader with a clear and comprehensive understanding of the description and evaluation of alternative applications of booster or maintenance interventions with children and adolescents. In addition, we hope that the series helps to frame some of the critical research and practice directions that should be addressed to enhance the careful study and successful incorporation of these conditions in routine clinical practice.

Acknowledgements This paper was supported, in part, by Grant 57727. We acknowledge the assistance of Jessica Laubach in the preparation of this paper.

\section{References}

Boggs, S. R., Eyberg, S. M., Edwards, D., Rayfield, A., Jacobs, J., Bagner, D., \& Hood, K. (2004). Outcomes of parent-child interaction therapy: a comparison of dropouts and treatment completers one to three years after treatment. Child \& Family Behavior Therapy, 26(4), 1-22.

Bor, W., Sanders, M. R., \& Markie-Dadds, C. (2002). The effects of the triple P-positive parenting program on preschool children with disruptive behavior and attentional problems. Journal of Abnormal Child Psychology, 30(6), 571-587.

Chamberlain, P., Fisher, P. A., \& Moore, K. J. (2002). Multidimensional treatment foster care: applications of the OSLC intervention model to high-risk youth and their families. In J. B. Reid, G. R. Patterson, \& J. Snyder (Eds.), Antisocial behavior in children: developmental theories and models for intervention (pp. 203-218). Washington, DC: American Psychological Association.

Dishion, T. J., Brennan, L. M., Shaw, D. S., McEachern, A. D., Wilson, M. N., \& Jo, B. (2013). Prevention of problem behavior through annual family check-ups in early childhood: intervention effects from home to early elementary school. Journal of Abnormal Child Psychology. doi:10.1007/s10802-013-9768-2.

Eyberg, S. M., Edwards, D., Boggs, S. R., \& Foote, R. (1998). Maintaining the treatment effects of parental training: the role of booster sessions and other maintenance strategies. Clinical Psychology-Science \& Practice, 5(4), 544-554.

Eyberg, S. M., Nelson, M. M., \& Boggs, S. R. (2008). Evidence-based psychosocial treatments for children and adolescents with disruptive behavior. Journal of Clinical Child and Adolescent Psychology, 37, 215-237.

Eyberg, S., Boggs, S., \& Jaccard, J. (2014). Does maintenance treatment matter? Journal of Abnormal Child Psychology. doi:10.1007/ s10802-013-9842-9.

Henggeler, S. W., Melton, G. B., Smith, L. A., Schoenwald, S. K., \& Hanley, J. H. (1993). Family preservation using multisystemic treatment: long-term follow-up to a clinical trial with serious juvenile offenders. Journal of Child and Family Studies, 2, 283293.

Hood, K. K., \& Eyberg, S. M. (2003). Outcomes of parent-child interaction therapy: mothers' reports on maintenance three to six years after treatment. Journal of Clinical Child and Adolescent Psychology, 32, 419-429.

Horne, A. M., \& Van Dyke, B. (1983). Treatment and maintenance of social learning family therapy. Behavior Therapy, 14(5), 606-613. doi:10.1016/S0005-7894(83)80053-7.

Kazdin, A. E., Bass, D., Siegel, T., \& Thomas, C. (1989). Cognitivebehavioral therapy and relationship therapy in the treatment of children referred for antisocial behavior. Journal of Consulting and Clinical Psychology, 57(4), 522-35.

Kazdin, A. E., Esvelt-Dawson, K., French, N. H., \& Unis, A. S. (1987a). Effects of parent management training and problem solving skills training combined in the treatment of antisocial child behavior. Journal of the American Academy of Child and Adolescent Psychiatry, 26, 416-424.

Kazdin, A. E., Esveldt-Dawson, K., French, N. H., \& Unis, A. S. (1987b). Problem-solving skills training and relationship therapy in the treatment of antisocial child behavior. Journal of Consulting and Clinical Psychology, 55, 76-85.

Kolko, D. J., Lindhiem, O., Hart, J., \& Bukstein, O. G. (2013). Evaluation of a booster intervention three years after acute treatment for earlyonset disruptive behavior disorders. Journal of Abnormal Child Psychology. doi:10.1007/s10802-013-9724-1.

Larsson, B., Fossum, S., Clifford, G., Drugli, M. B., Handegård, B. H., \& Mørch, W. T. (2009). Treatment of oppositional defiant and conduct problems in young Norwegian children: results of a randomized controlled trial. European Child \& Adolescent Psychiatry, 18(1), 42-52. doi:10.1007/s00787-008-0702-z.

Lochman, J. E. (1992). Cognitive-behavioral intervention with aggressive boys: three-year follow-up and preventive effects. Journal of Consulting and Clinical Psychology, 60, 426-32.

Lochman, J. E., Baden, R. E., Boxmeyer, C. L., Powell, N. P., Qu, L., Salekin, K. L., et al. (2013). Does a booster intervention augment the preventive effects of an abbreviated version of the coping power program for aggressive children? Journal of Abnormal Child Psychology. doi:10.1007/s10802-013-9727-y

Reid, M. J., Webster-Stratton, C., \& Hammond, M. (2003). Follow-up of children who received the incredible years intervention for oppositional-defiant disorder: maintenance and prediction of 2year outcome. Behavior Therapy, 34, 471-491.

Tolan, P. H. (2014). More than afterthoughts and details: maintenance and booster effects as critical elements of intervention research. Journal of Abnormal Child Psychology. doi:10.1007/s10802-013-9839-4.

Tolan, P. H., Gorman-Smith, D., Henry, D., \& Schoeny, M. (2009). The benefits of booster interventions: evidence from a family-focused prevention program. Prevention Science, 10, 287-297. doi:10.1007/ s11121-009-0139-8.

Webster-Stratton, C. (1984). A randomized trial of two parent-training programs for families with conduct-disordered children. Journal of Consulting and Clinical Psychology, 52, 666-678. 